\title{
Metabolic engineering of the cellulolytic thermophilic fungus Myceliophthora thermophila to produce ethanol from cellobiose
}

Jinyang $\mathrm{Li}^{1,2+}$, Yongli Zhang ${ }^{1,2+}$, Jingen $\mathrm{Li}^{1}$, Tao Sun ${ }^{1}$ and Chaoguang $\operatorname{Tian}^{1 *}$

\begin{abstract}
Background: Cellulosic biomass is a promising resource for bioethanol production. However, various sugars in plant biomass hydrolysates including cellodextrins, cellobiose, glucose, xylose, and arabinose, are poorly fermented by microbes. The commonly used ethanol-producing microbe Saccharomyces cerevisiae can usually only utilize glucose, although metabolically engineered strains that utilize xylose have been developed. Direct fermentation of cellobiose could avoid glucose repression during biomass fermentation, but applications of an engineered cellobiose-utilizing $S$. cerevisiae are still limited because of its long lag phase. Bioethanol production from biomass-derived sugars by a cellulolytic filamentous fungus would have many advantages for the biorefinery industry.

Results: We selected Myceliophthora thermophila, a cellulolytic thermophilic filamentous fungus for metabolic engineering to produce ethanol from glucose and cellobiose. Ethanol production was increased by $57 \%$ from glucose but not cellobiose after introduction of SCADH1 into the wild-type (WT) strain. Further overexpression of a glucose transporter GLT-1 or the cellodextrin transport system (CDT-1/CDT-2) from N. crassa increased ethanol production by $131 \%$ from glucose or by $200 \%$ from cellobiose, respectively. Transcriptomic analysis of the engineered cellobioseutilizing strain and WT when grown on cellobiose showed that genes involved in oxidation-reduction reactions and the stress response were downregulated, whereas those involved in protein biosynthesis were upregulated in this effective ethanol production strain. Turning down the expression of pyc gene results the final engineered strain with the ethanol production was further increased by $23 \%$, reaching up to $11.3 \mathrm{~g} / \mathrm{L}$ on cellobiose.

Conclusions: This is the first attempt to engineer the cellulolytic fungus $M$. thermophila to produce bioethanol from biomass-derived sugars such as glucose and cellobiose. The ethanol production can be improved about 4 times up to 11 grams per liter on cellobiose after a couple of genetic engineering. These results show that $M$. thermophila is a promising platform for bioethanol production from cellulosic materials in the future.
\end{abstract}

Keywords: Myceliophthora thermophila, Ethanol, Cellobiose, RNA-seq, Sugar uptake, Metabolic engineering

*Correspondence: tian_cg@tib.cas.cn

${ }^{\dagger}$ Jinyang Li and Yongli Zhang contributed equally to this work

${ }^{1}$ Key Laboratory of Systems Microbial Biotechnology, Tianjin Institute

of Industrial Biotechnology, Chinese Academy of Sciences, Tianjin 300308, China

Full list of author information is available at the end of the article

\section{Background}

Lignocellulose, which is mainly composed of polymers of glucose and xylose, is the most abundant carbohydrate resource on earth and is a major renewable feedstock for biorefinery [1]. Conversion of lignocellulose into biofuels such as ethanol is an important strategy for sustainable development. Extensive efforts have been made to engineer microorganisms to produce biofuels or chemicals from lignocellulose. However, the high

(c) The Author(s) 2020. This article is licensed under a Creative Commons Attribution 4.0 International License, which permits use, sharing, adaptation, distribution and reproduction in any medium or format, as long as you give appropriate credit to the original author(s) and the source, provide a link to the Creative Commons licence, and indicate if changes were made. The images or other third party material in this article are included in the article's Creative Commons licence, unless indicated otherwise in a credit line to the material. If material is not included in the article's Creative Commons licence and your intended use is not permitted by statutory regulation or exceeds the permitted use, you will need to obtain permission directly from the copyright holder. To view a copy of this licence, visit http://creativecommons.org/licenses/by/4.0/. The Creative Commons Public Domain Dedication waiver (http://creativecommons.org/publicdomain/zero/1.0/) applies to the data made available in this article, unless otherwise stated in a credit line to the data. 
costs of cellulose-to-sugar conversion and inefficient fermentation of both hexose and pentose sugars have made commercial production economically unattractive. Plant biomass hydrolysates consist of approximately $70 \%$ cellodextrins and glucose and 30\% xylose [2]. Hydrolysis of cellulose by fungal cellulases primarily generates cellobiose, which can be further hydrolyzed to glucose by $\beta$-glucosidases. Therefore, organisms capable of efficiently utilizing cellodextrins and glucose are desired to produce biofuels from cellulosic biomass [3]. However, a high concentration of glucose inhibits cellulase activity and the fermentation of non-glucose sugars present in cellulosic hydrolysates because of carbon catabolic repression (CCR). Therefore, direct fermentation of cellodextrins is a better approach. The intracellular hydrolysis of cellobiose can relieve the effect of CCR on the utilization of other sugars during co-fermentation. However, S. cerevisiae cannot ferment the cellodextrins that are naturally released by cellulases. To engineer strains capable of fermenting cellobiose, researchers have introduced various heterologous pathways into $S$. cerevisiae. Such pathways include cellobiose utilization pathways consisting of a cellobiose transporter system (CDT-1 or CDT-2 from $N$. crassa) and either a hydrolytic enzyme (GH1-1, $\beta$-glucosidase from $N$. crassa) or a phosphorolytic enzyme (CBP, cellobiose phosphorylase from Saccharophagus degradans) [4-6]. The initially engineered $S$. cerevisiae strain had a minimal synthetic biological module consisting of only CDT-1 and GH1-1. This strain could ferment cellobiose, but is still inferior to consumption of extracellular glucose in terms of rate and results in a prolonged lag phase [7]. The addition of a functional xylose metabolic pathway resulted in a strain that was able to co-ferment xylose and cellobiose [8]. Further efforts to increase the rate of cellobiose fermentation have included combinatorial transcriptional engineering [9], experimental evolution [10-14], exploration and optimization of cellodextrin transporters $[15,16]$, and the manipulation of transcription factors [7]. Despite these engineering efforts, cellobiose fermentation by S. cerevisiae is still very limited. In contrast, cellulolytic fungi such as $M$. thermophila naturally use cellobiose efficiently.

Thermophilic fungi are excellent producers of thermostable enzymes for industrial applications and can potentially be developed into cell factories to produce chemicals and materials at elevated temperatures. $M$. thermophila is a thermophilic filamentous fungus that can produce a variety of carbohydrate-active enzymes (CAZymes) involved in the degradation of a wide range of biomass sources $[17,18]$. Such enzymes can potentially be used in the production of biofuels and chemicals. The fermentation characteristics of $M$. thermophila are suitable for large-scale production [19]. In addition, the availability of its genomic sequence [17] and well-developed genetic tools [20-22] allow for targeted genetic engineering of this thermophilic fungus for the production of biochemicals. Recently, M. thermophila was engineered to produce fumaric acid efficiently from glucose [23] and C4-dicarboxylic acids from cellulose and corn cob [24], indicating that $M$. thermophila is a promising system for chemical and fuel production.

Here, we evaluated the transcriptional response of M. thermophila to cellobiose during fermentation and constructed strains with enhanced ethanol production. Increasing the sugar-uptake capability significantly increased ethanol production from cellobiose by the fungus to almost $10 \mathrm{~g} / \mathrm{L}$, approximately three times that produced by the wild-type (WT) strain. A transcriptomic analysis revealed large-scale transcriptional changes in the engineered efficient cellobiose-utilizing strain, with reduced expression of genes involved in oxidationreduction reactions and the stress response pathway, and increased expression of genes involved in amino acid biosynthesis. Our results show that the cellulolytic fungus M. thermophila is a promising new platform for bioethanol production from cellulosic materials, especially after further metabolic engineering using a consolidated bioprocessing (CBP) strategy to produce strains with high cellulase activity and ethanol fermentation rates.

\section{Results}

\section{Evaluation of ethanol tolerance of $M$. thermophila}

Ethanol tolerance is an important consideration when selecting a host for ethanol production, because it is a critical factor affecting the ability of the microorganism to generate economically viable quantities of ethanol. To assess the feasibility of using the thermophilic fungus $M$. thermophila as an ethanol production system, its ethanol tolerance was determined by inoculating either spores or pre-grown mycelia into fermentation medium containing $7.5 \%$ glucose and different concentrations of ethanol and then determining the dry cell weight (DCW) after a defined culture period.

When spores were used as the inoculum, mycelia could grow normally in media containing $10 \mathrm{~g} / \mathrm{L}$ and $20 \mathrm{~g} / \mathrm{L}$ ethanol with no observed defects. Mycelia grew moderately in medium containing $30 \mathrm{~g} / \mathrm{L}$ ethanol, but could not grow in medium containing $40 \mathrm{~g} / \mathrm{L}$ ethanol (Fig. 1a).

The ethanol tolerance of pre-grown mycelia was also determined. As shown in Fig. 1b, mycelia could re-grow in medium containing $40 \mathrm{~g} / \mathrm{L}$ ethanol, but there was a lag phase. Mycelia did not grow in medium containing $50 \mathrm{~g} / \mathrm{L}$ ethanol, but were still viable after $12 \mathrm{~h}$ in that medium (Fig. 1c), suggesting that M. thermophila can 

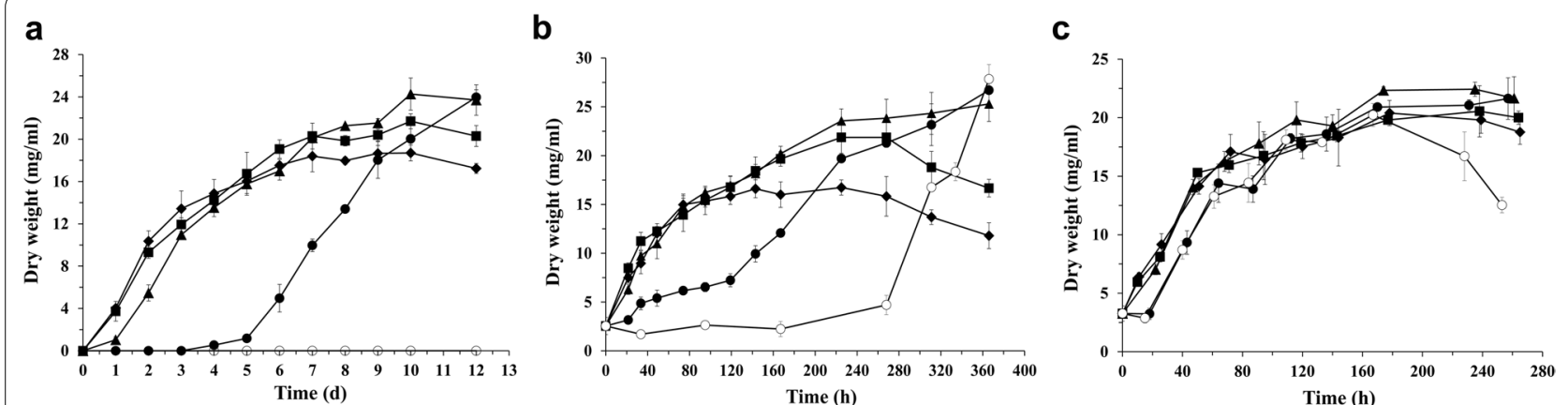

Fig. 1 Determination of ethanol tolerance of M. thermophila. a Spores were inoculated into fermentation medium $\left(2.5 \times 10^{5} / \mathrm{mL}\right) \mathrm{containing}$ different concentration of ethanol. b Spores were inoculated into fermentation medium $\left(2.5 \times 10^{5} / \mathrm{mL}\right)$ and grown for $20 \mathrm{~h}$, and then mycelia were transferred to fresh fermentation medium containing different concentration of ethanol. Ethanol concentration used were $0 \mathrm{~g} / \mathrm{L}$ (closed diamond), $10 \mathrm{~g} / \mathrm{L}$ (closed square), $20 \mathrm{~g} / \mathrm{L}$ (closed triangle, $30 \mathrm{~g} / \mathrm{L}$ (closed circle) and $40 \mathrm{~g} / \mathrm{L}$ (open circle). c Spores were inoculated into fermentation medium $\left(2.5 \times 10^{5} / \mathrm{ml}\right)$ and grown for $24 \mathrm{~h}$. Ethanol was added to a final concentration of $50 \mathrm{~g} / \mathrm{L}$. After incubation for $1 \mathrm{~h}$ (closed diamond), $2 \mathrm{~h}$ (closed square), $5 \mathrm{~h}$ (closed triangle), $9 \mathrm{~h}$ (closed circle) and $12 \mathrm{~h}$ (open circle), mycelia were transferred to fresh fermentation medium. Culture conditions: $48^{\circ} \mathrm{C}$, shaking at $150 \mathrm{rpm}$. Dry cell weight (DCW) was determined at end of culture period. Error bars represent SD from three replicates

tolerate up to $50 \mathrm{~g} / \mathrm{L}$ ethanol. This is a relatively high level of ethanol tolerance.

At the end of the culture period, the DCW was higher in media containing $10-30 \mathrm{~g} / \mathrm{L}$ ethanol than in medium containing no ethanol, and higher in media containing 20-30 g/L ethanol than in medium containing $10 \mathrm{~g} / \mathrm{L}$ ethanol (Fig. 1a, b). These results indicate that $M$. thermophila is able to use ethanol as a carbon source after glucose is depleted.

\section{Comparison of transcriptomes of $M$. thermophila WT between cellobiose vs. D-glucose as carbon source}

Myceliophthora thermophila utilizes cellobiose as fast as glucose. There are certain advantages of engineering $M$. thermophila to produce ethanol from cellobiose, a non-repressing sugar, rather than from glucose. To gain further insights into cellobiose utilization by this thermophilic fungus, we compared the transcriptional responses of the M. thermophila WT strain between cultures with cellobiose and glucose as the carbon source. The transcriptomes of $M$. thermophila growing in media containing glucose and cellobiose were prepared by the RNA-sequencing technique. Clean reads were mapped to the $M$. thermophila genome sequence and reads per kilobase of exon model per million mapped reads (RPKMs) were calculated as the normalized expression values of each annotated gene. Differential expression analysis was conducted using DESeq [25] (Additional file 1: Table S2). Pearson correlation analysis demonstrated that the biological replicates were reliable for all tested samples (Additional file 1: Table S3).

Compared with D-glucose as the carbon source, cellobiose resulted in the significant differential expression of 742 genes at 3-day and 5-day fermentation, of which 388 genes were upregulated and 354 genes were downregulated. There were 185 upregulated genes and 139 downregulated genes common to the 3-day and 5-day cultures, respectively (Fig. 2a). Gene ontology (GO) analysis showed that, among the 185 upregulated genes, those involved in cellulose degradation were the most enriched category (Fig. 2b and Additional file 1: Table S4). This category included the following 15 cellulase genes: Mycth_109566 (orthologous to cbh-1 NCU07340), Mycth_66729 (orthologous to $c b h-2$ NCU09680), Mycth_115968 ( $\beta$-glucosidase, orthologous to gh1-1 NCU00130), Mycth_62925 ( $\beta$-glucosidase, orthologous to gh3-6 NCU07487), Mycth_83041 (orthologous to gh76-3 NCU08127), Mycth_110651 (orthologous to gh61-7 NCU00836), and two hemicellulase genes ( $\beta$-xylosidase Mycth_80104, orthologous to gh43-5 NCU09652 and endoxylanase Mycth_116553, orthologous to gh10-2 NCU08189). Compared with glucose as the carbon source, cellobiose resulted in upregulated expression of four transcription factors that regulate cellulase expression (Mycth_38704 orthologous to $c l r$-2 NCU08042, Mycth_2305813 orthologous to $c l r$ 3 NCU05846, Mycth_2301920 orthologous to col-26 NCU07788, and Mycth_2310145 orthologous to xlr-1 NCU06971), two genes encoding cellodextrin transporters (Mycth_114107, orthologous to cdt-2 NCU08114 and Mycth_84164, orthologous to clp1 NCU05853), one gene encoding a high-affinity glucose transporter (Mycth_2308157 orthologous to hgt-1 NCU10021) (Fig. 2c). Mycth_38704 (clr-2), Mycth_2305813 (clr3), Mycth_2310145 (xlr-1), Mycth_114107 (cdt-2), and Mycth_84164 (clp1) are components of the "Mt Avicel regulon" [26] and their orthologs in $N$. crassa are components of the "Nc Avicel regulon" [27]. CLR-2, CLR-3, 


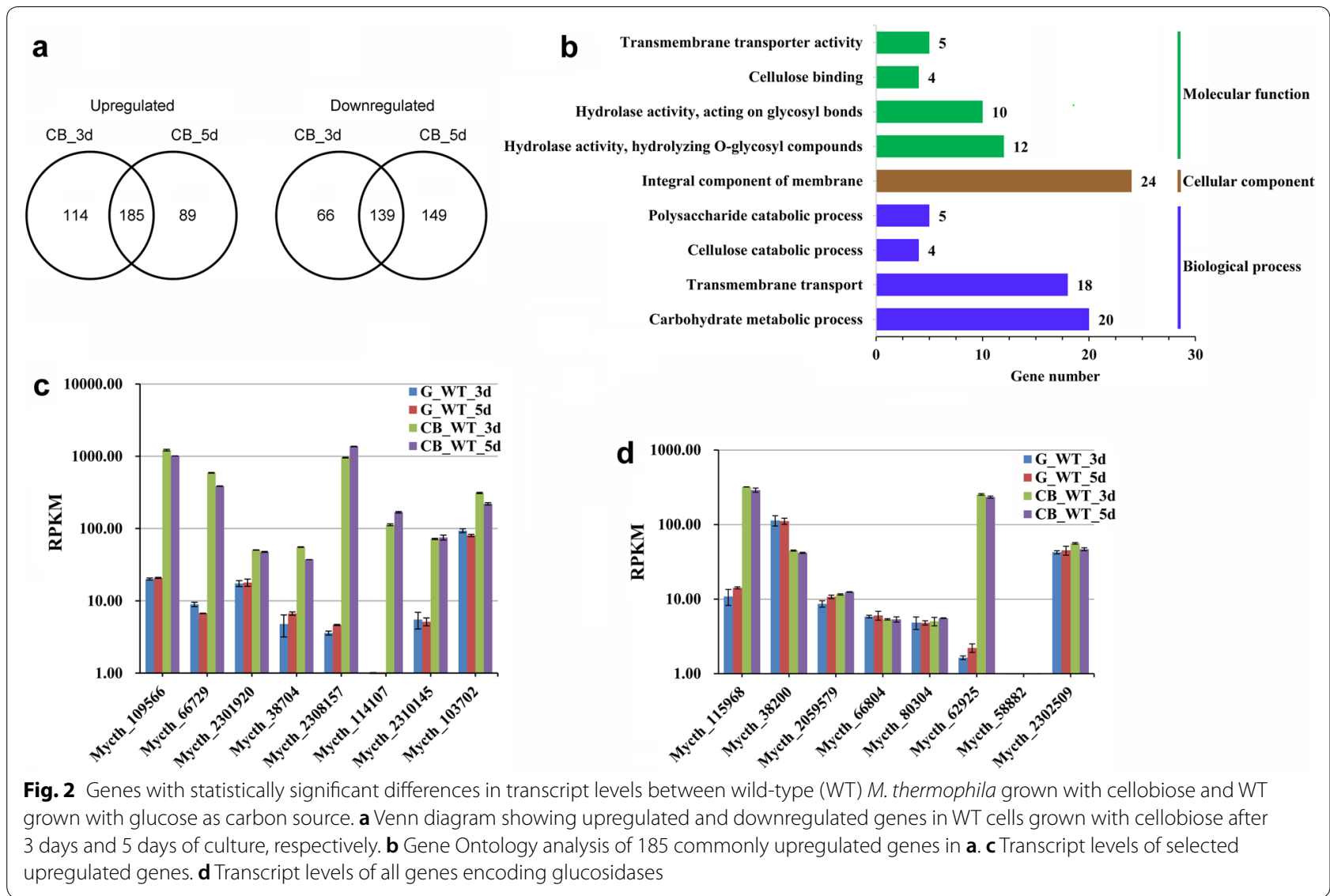

XLR-1, CDT-2, and CLP1 are known to play essential roles in (hemi)-cellulose utilization by $N$. crassa [27-31]. Mycth_2301920, which was significantly induced by cellobiose as the carbon source, is the M. thermophila ortholog of the $\mathrm{Zn}$ (II)2Cys6 transcription factors AmyR in Aspergillus and COL-26 in N. crassa, which are essential for starch utilization [32-34].

Interestingly, a gene encoding aldose 1-epimerase (AEP, Mycth_103702 orthologous to NCU08398), which catalyzes the interconversion between $\beta$-form and $\alpha$-form sugars, was significantly upregulated in $M$. thermophila cultured with cellobiose, compared with that cultured with glucose. Previously, this gene was significantly upregulated when plant biomass was used as the carbon source [35]. Similarly, in N. crassa, the gene encoding AEP (NCU08398) was significantly induced by biomass and Avicel [27, 36, 37], indicating that high AEP expression may allow cellulolytic fungi to utilize cellobiose as well as plant biomass. Interestingly, the deletion of GAL10 (encoding aldose 1-epimerase) from the engineered cellobiose-utilizing $S$. cerevisiae expressing CDT-1 and GH1-1 led to the complete loss of cell growth on cellobiose [38]. To investigate the role of AEP in cellobiose utilization of $M$. thermophila, we constructed the aep disruption mutant ( $\triangle a e p)$ by CRISPR/Cas 9 system (Additional file 2: Fig. S1a). Four mutants were randomly selected for growth assay. There were no differences of growth on glucose or cellobiose between $\Delta a e p$ mutants and WT strain (Additional file 2: Fig. S1b). When cultured in fermentation media containing $7.5 \%$ glucose or cellobiose, the ethanol production of $\Delta a e p$ mutants was reduced by $75 \%$ and $43 \%$, respectively (Additional file 2 : Fig. S1c). The biomass of $\Delta a e p$ mutants was not reduced, even better when glucose was used (Additional file 2: Fig. S1d). These results implicated the functional discrepancy of AEP among species.

In $N$. crassa, cellobiose induced the expression of lignocellulolytic genes in an engineered strain with three deleted $\beta$-glucosidase genes, but not in the WT strain [39]. Of the 185 upregulated genes in $M$. thermophila cultured with cellobiose as the carbon source, 36 encoded components of the "Mt Avicel regulon". Seven of those genes were among 38 genes showing increased expression levels under starvation conditions in another study [34]. Three of the seven genes (Mycth_66729, Mycth_115968, and Mycth_103702) showed similar moderate induction with cellobiose as the carbon source and under starvation conditions. The transcript levels 
of the other four genes (Mycth_110651, Mycth_84164, Mycth_114107 and Mycth_5342) were much higher on cellobiose medium (Additional file 1: Table S4) [34]. These data indicate that the induction of these 185 genes in M. thermophila by cellobiose is due to a combination of relief from CCR and the presence of an inducer (cellobiose), like the response of $N$. crassa to xylan as the carbon source [29].

Of the eight genes encoding $\beta$-glucosidases, only Mycth_115968 and Mycth_62925 with no predicted secretory signal peptides were induced by cellobiose (Fig. 2d). In previous studies, two genes encoding intracellular $\beta$-glucosidases were also induced by Avicel [26] and plant biomass [35], indicating that they are the most relevant enzymes for converting cellobiose to glucose when $M$. thermophila is cultured with either cellobiose or plant-derived biomass as the sole carbon source.

Of the 139 downregulated genes in M. thermophila cultured with cellobiose as the carbon source, those involved in ammonium transport, nitrogen metabolism, and membranes were the most enriched (Additional file 1: Table S5), suggesting a probable correlation between carbon and nitrogen metabolism in M. thermophila, as is the case in N. crassa [33].

Cellobiose can also be cleaved to glucose-1-phosphate and glucose by cellobiose phosphorylase. The genome of $M$. thermophila contains only one predicted gene (Mycth_2308030, Mtcpp) encoding cellobiose phosphorylase, orthologous to $n d v B$ (NCU09425) from N. crassa which encodes a cellobionate phosphorylase. $n d v B$ was shown to be involved in cellobionate and cellobiose utilization in N. crassa [40, 41]. Recently, the role of MtCPP was investigated and showed that MtCPP is indeed the functional component of cellobiose phosphorolytic pathway [42]. However, the transcript levels of Mtcpp were not induced by cellobiose in M. thermophila WT strain (Additional file 1: Table S2) but in an engineered malateproducing strain JG207 [42].

The differentially expressed genes in M. thermophila between cellobiose and glucose as the carbon source included a few genes involved in central carbon metabolism pathways. To explore this in more detail, the transcript levels of three hexokinase genes (Mycth_2297364, Mycth_2295756 and Mycth_2306777) were analyzed. Compared with cells grown with glucose as the carbon source, those grown with cellobiose showed increased transcript levels of Mycth_2297364 (by 3.1- and 6.8-fold at 3 day and 5 day, respectively) but no difference in the transcript levels of Mycth_2295756 and Mycth_2306777 (Additional file 1: Table S2). Similarly, Hxk1 of S. cerevisiae was highly transcribed in cellobiose-grown cells [7]. Mycth_2297364 also showed elevated transcript levels in cells grown with glucose, starch, and Avicel compared with cells grown in starvation conditions $[26,34]$. These data indicate that Mycth_2297364 is the predominant isoenzyme when cells are grown with fermentable carbon sources. Its elevated expression in cells cultured with cellobiose as the carbon source may contribute to efficient utilization of this substrate. Other genes in central carbon metabolic pathways showing significant differential expression between glucose and cellobiose conditions included those encoding a trehalose-6-phosphate synthase (Mycth_2309547), a glycogen phosphorylase (Mycth_2309843), and an isocitrate lyase (Mycth_110871).

\section{Engineering of $M$. thermophila to produce ethanol from cellobiose}

The genome of $M$. thermophila contains genes encoding a pyruvate decarboxylase (Mycth_112121) and a number of alcohol dehydrogenases, indicating that ethanol can be produced from pyruvate. In standard fermentation medium, the $M$. thermophila WT strain produced around $3 \mathrm{~g} / \mathrm{L}$ ethanol with glucose or cellobiose as the carbon source. This confirmed that the ethanol production pathway is functional in this thermophilic fungus, which encouraged us to engineer this cellulolytic fungus as a new ethanol producer.

We speculated that its glycolytic flux is not fast enough to drive ethanol production efficiently. In S. cerevisiae, if upper glycolysis (upstream of fructose 1,6-bisphosphate) outpaces lower glycolysis (downstream of fructose 1,6-bisphosphate), an imbalanced state with reduced ATP production occurs [43]. Therefore, we first introduced S. cerevisiae Adh1 (ScAdh1, without codon optimized), which encodes an alcohol dehydrogenase (ADH) that catalyzes the conversion of acetaldehyde into ethanol, into the $M$. thermophila WT strain to accelerate lower glycolysis. The copy number of the chromosomally integrated ScAdh1 in the transformants was determined by real-time quantitative PCR. Strain JY144, which produced the highest titer of ethanol among the transformants (Additional file 3: Fig. S2a), harbored 3 copies of ScAdh1 (Additional file 3: Fig. S2c) and was chosen for further engineering. JY144 produced $5.06 \mathrm{~g} / \mathrm{L}$ ethanol from glucose, representing a $57 \%$ increase compared with the WT strain (Fig. 3a). The alcohol dehydrogenase activity of JY144 strain was $40 \%$ higher than that of WT strain $(0.78 \pm 0.06 \mathrm{U} / \mathrm{mg}$ vs. $0.55 \pm 0.08 \mathrm{U} / \mathrm{mg})$, indicating that the enhanced ADH activity contributed to the increased ethanol production in JY144. We further introduced the $N$. crassa low-affinity glucose transporter GLT-1 (NCU01633, without codon optimized) into JY144 to enhance glucose transport. The resulting strain JY206 (produced the highest titer of ethanol among the transformants with 4 copies of $g l t-1$ (Additional file 3: Fig. S2b, 

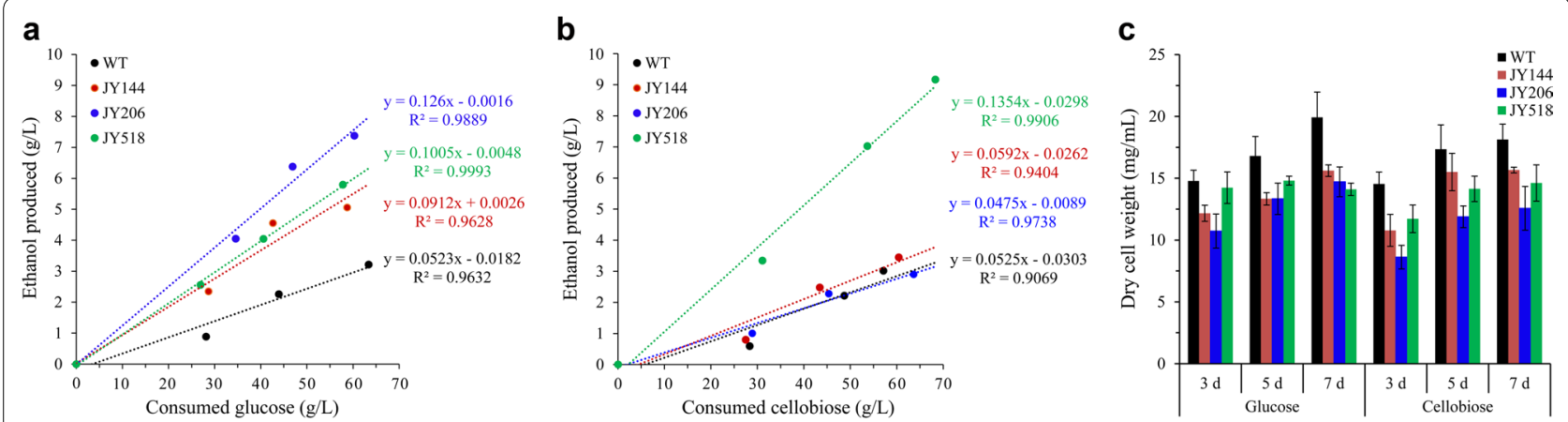

Fig. 3 Profiles of ethanol produced and sugar consumed by M. thermophila strains grown with glucose (a) and cellobiose (b) as carbon source. Biomass of corresponding strains is shown in c. Strains were cultured at $48^{\circ} \mathrm{C}$ with shaking at $150 \mathrm{rpm}$. Error bars represent SD from three replicates
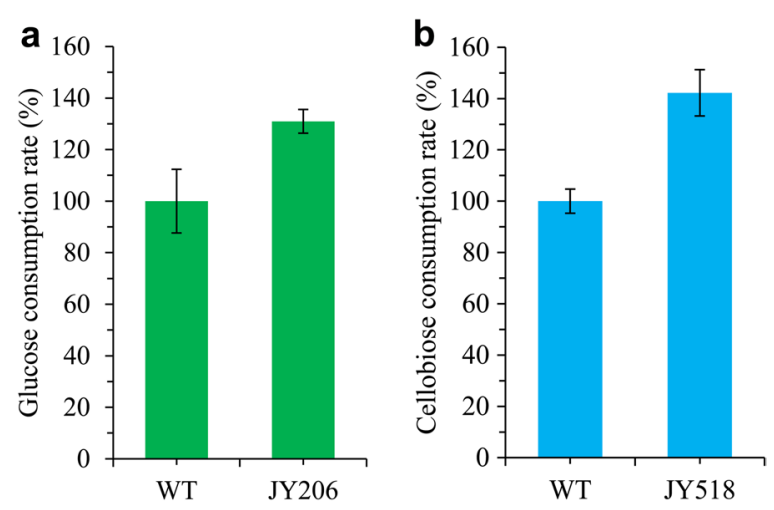

Fig. 4 Assay of sugar consumption rate for glucose (a) and cellobiose (b)

d) showed improved ethanol production $(7.4 \mathrm{~g} / \mathrm{L}$ from glucose) compared with $3.2 \mathrm{~g} / \mathrm{L}$ produced by the WT strain (Fig. 3a). The glucose consumption rate of JY206 increased by $31 \%$ compared to WT strain (Fig. 4a). Surprisingly, when cellobiose was supplied as the carbon source, JY144 and JY206 performed no better than WT in terms of ethanol production (Fig. 3b), suggesting that some other engineering strategies should be considered for cellobiose fermentation.

We speculated that increasing the intracellular cellobiose concentration might increase ethanol production if the native cellodextrin transporters do not take up enough cellobiose for strong glycolytic flux towards ethanol production. Since cellobiose consumption was found to be strongly correlated with ethanol production rates in cellobiose-utilizing $S$. cerevisiae (Ha et al. [10]), we introduced the cellodextrin transporters CDT-1/-2 without codon optimized from the filamentous fungus $N$. crassa into JY144 strain. CDT1/-2 can work heterologously in S. cerevisiae, so we introduced them into two lactate dehydrogenase gene sites, Mycth_38939 and Mycth_110317, respectively, in M. thermophila. This resulted in the addition of two new cellodextrin transporters as well as the disruption of a potential lactate production pathway. The resulting strain JY518 showed significantly improved ethanol production from cellobiose $(9.2 \mathrm{~g} / \mathrm{L}$, approximately three times that of the WT strain) (Fig. 3b). The cellobiose consumption rate of JY518 increased by $42 \%$ compared to WT strain (Fig. 4b). When glucose was used as the carbon source, the ethanol production of JY518 was no different from that of JY144, maybe because CDT-1/-2 do not have glucose uptake activity. The correlation between the sugar consumption and ethanol production was observed in the tested strains (Fig. 3a, b). The engineered strains converted more carbon flux towards ethanol production which was more obvious if the biomass was taken into consideration, since the less biomass was observed in strains with higher ethanol production (Fig. 3c). Co-consumption of glucose and cellobiose by JY518 strain was also investigated. Compared to WT strain which only utilized cellobiose after glucose was depleted, JY518 was capable of co-utilizing these two sugars and also producing more ethanol than WT strain $(6.9 \pm 0.3 \mathrm{~g} / \mathrm{L}$ vs. $2.2 \pm 0.2 \mathrm{~g} / \mathrm{L})$ (Fig. $5 \mathrm{a})$.

All the engineered strains showed reduced biomass compared with that of WT, regardless of whether the carbon source was glucose or/and cellobiose (Figs. 3c, 5b). In S. cerevisiae, overexpression of most glycolytic proteins was found to cause growth defects [44]. We speculated that overexpression of heterologous proteins in the M. thermophila strains negatively affected their growth. These results indicate that enhancing sugar uptake is a useful approach to increase the glycolytic flux to ethanol production, despite the adverse effects of heterologous protein overexpression on growth. 

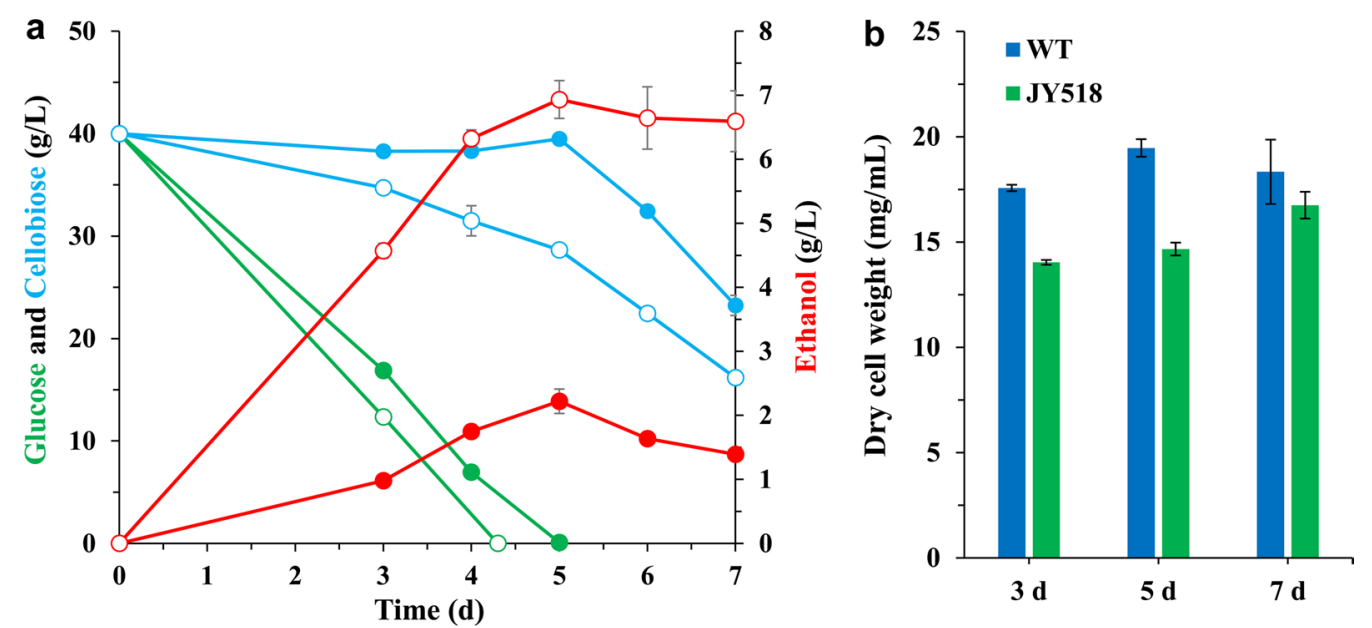

Fig. 5 Co-fermentation of glucose and cellobiose by WT (closed circle) and JY518 strain (open circle). a Fermentation profiles during the fermentation of sugar mixtures containing $40 \mathrm{~g} / \mathrm{L}$ of glucose and $40 \mathrm{~g} / \mathrm{L}$ of cellobiose. $\mathbf{b}$ Dry weights of mycelia in the culture during fermentation

\section{Comparative transcriptional analysis of WT and JY518 with cellobiose as carbon source}

To investigate the gene expression profile of the effective ethanol production strain JY518 during cellobiose utilization, we compared its transcriptome with that of the WT strain with cellobiose as the carbon source. We found that 1051 genes were upregulated and 710 genes were downregulated at either 3 day or 5 day of culture in JY518 (Fig. 6a and Additional file 1: Table S2). Among the 710 downregulated genes, those involved in oxidationreduction reactions, integral membrane components, transmembrane transport, response to stress, and carbohydrate metabolism were the most enriched (Fig. 6b and Additional file 1: Table S6). Among the downregulated genes was a group of genes encoding various products with a FAD-binding domain, such as Mycth_39133, Mycth_2140533, Mycth_2299483, Mycth_73194, Mycth_2297213, Mycth_109870 and Mycth_70573. Both Mycth_2140533 and Mycth_109870 are orthologous to sol5 gene of Alternaria solani encoding solanapyrone synthase involved in secondary metabolite solanapyrone A biosynthesis [45]. Mycth_73194 is orthologous to $p v d A$ of Pseudomonas aeruginosa encoding L-ornithine $\mathrm{N}(5)$-oxygenase involved in pyoverdine siderophore biosynthesis [46]. Mycth_39133 encodes a putative D-aspartate oxidase, Mycth_2297213 encodes a putative ferric-chelate reductase and Mycth_70573 encodes a putative pyridine nucleotide-disulphide oxidoreductase. This indicates the secondary metabolite pathways such as solanapyrone synthesis were weakened in engineered ethanol production strain on cellobiose. However, the exactly connections between secondary metabolism and ethanol production in engineered strain grown on cellobiose is not known now. The downregulated genes also included stress response-related genes (GO: 0006950) including Mycth_2133483, Mycth_2306260, and Mycth_80427. Mycth_2133483 is an ortholog of the S. cerevisiae ATP-dependent Hsp90 family molecular chaperones Hsc82 and Hsp82, which assist in the maturation of a large set of target proteins. Mycth_2306260 is an ortholog of S. cerevisiae Aha1, a co-chaperone that binds to Hsp82p and activates its ATPase activity [47]. In S. cerevisiae, ATP hydrolysis by $\mathrm{Hsp} 90$ is required to maintain its function [48, 49]. Mycth_80427 encodes a heat shock protein orthologous to S. cerevisiae Hsp104. During heat shock, Hsp104 contributes to the simultaneous increase in both the accumulation and degradation of trehalose in S. cerevisiae [50]. Trehalose plays a vital role in the heat shock response of S. cerevisiae and $M$. thermophila [51, 52]. Consistent with the downregulation of Mycth_80427 (hsp104), genes involved in trehalose biosynthesis (Mycth_2082262, Mycth_2295490, Mycth_2309547) were also downregulated in JY518 compared with WT grown with cellobiose as the carbon source (Fig. 6b and Additional file 1: Table S2). These results suggest that the heat stress response is probably impaired in JY518. Indeed, JY518 grew better than WT strain on cellobiose plates at elevated temperature but more sensitive to $\mathrm{H}_{2} \mathrm{O}_{2}$-induced oxidative stress (Additional file 4: Fig. S3a). The impaired response of JY518 strain to heat stress was more obvious when cultivated in fermentation media containing cellobiose at $55{ }^{\circ} \mathrm{C}$, since the better growth was observed in JY518 compared to WT strain (Additional file 4: Fig. S3b).

Genes involved in transcription, translation, and amino acid biosynthesis were the most enriched among the 


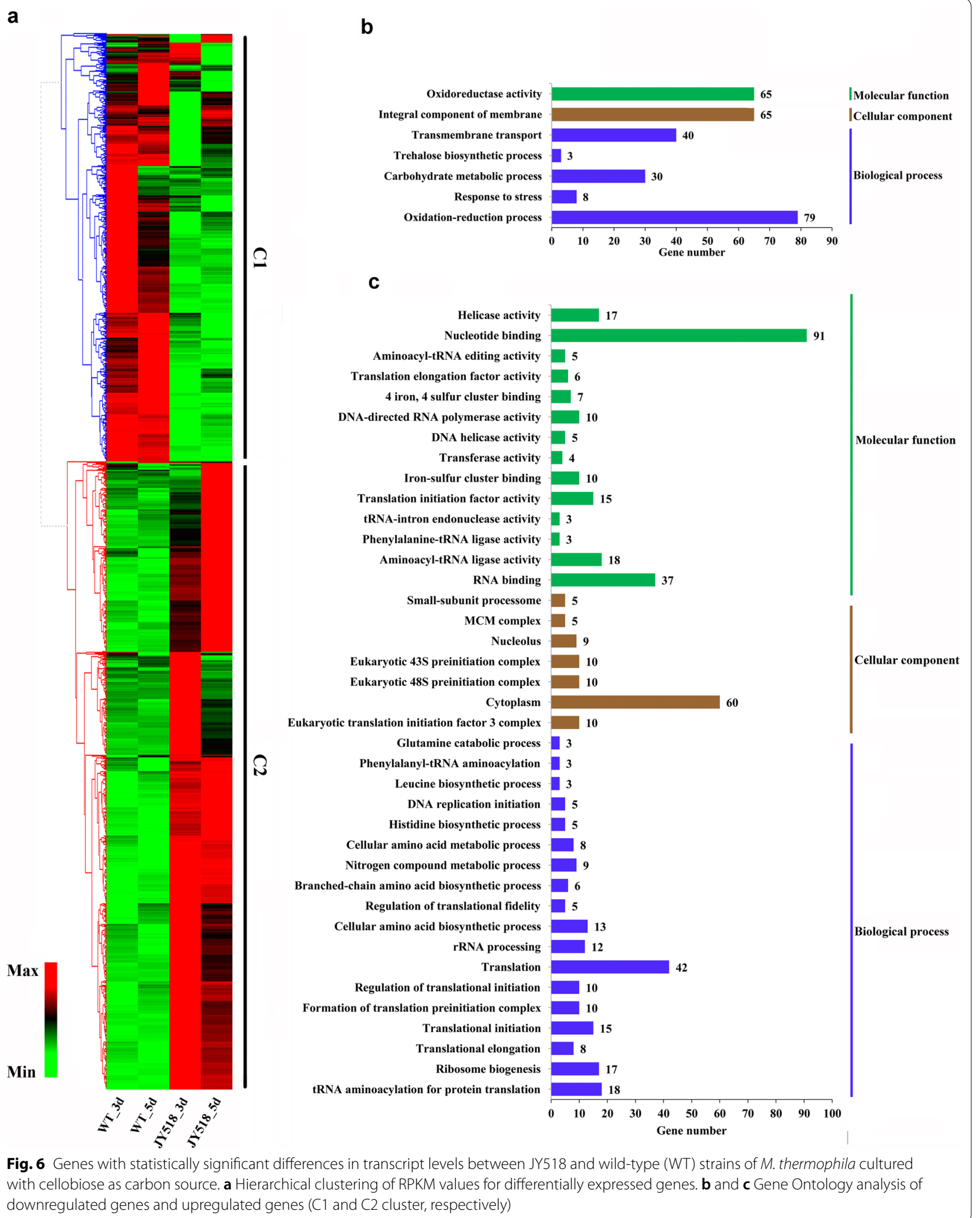


1051 upregulated genes in JY518 compared with WT grown with cellobiose as the carbon source (Fig. $6 \mathrm{c}$ and Additional file 1: Table S7). In engineered cellobiose-utilizing S. cerevisiae, cellobiose induces mitochondrial activation and reduces amino acid biosynthesis, compared with glucose as the substrate [7]. Our JY518 strain consumed more cellobiose and produced more ethanol than did the WT strain because of the faster glycolytic flux conferred by CDT-1/-2 (Fig. 3b). In JY518, genes involved in amino acid biosynthesis were induced (Fig. 6c). These results indicate a correlation between glycolytic flux and amino acid biosynthesis. Since WT M. thermophila showed comparable sugar consumption and ethanol production rates between glucose and cellobiose as the carbon source (Fig. 3a, b), glycolytic flux should be similar on both substrates in the WT. Consistently, the transcript levels of genes involved in amino acid biosynthesis showed no significant differences in WT between cellobiose and glucose as the carbon source (Additional file 1: Table S2). We speculated that the enhanced amino acid biosynthesis and translation in JY518 led to enhanced biosynthesis of enzymes involved in glycolysis, resulting in greater ethanol production from cellobiose in this engineered strain.

Next, we focused on genes involved in central metabolism. $f b p 1$, whose product catalyzes the conversion of fructose-1,6-bisphosphate (FBP) to fructose-6-phosphate, was significantly downregulated and pgam encoding phosphoglycerate mutase converting 3-phosphoglycerate into 2-phosphoglycerate was upregulated, indicating that glycolytic flux was indeed accelerated in JY518. The gpd gene in glycerol production pathway was upregulated at 5-day culture (Fig. 7). Consistently, the glycerol production of JY518 was higher than that of WT strain both at 5-day and 7-day cultivation (Additional file 5: Fig. S4). The $p y c$ gene, whose products catalyze the conversion of pyruvate to oxaloacetate, was also upregulated in JY518 (Fig. 7). Disruption of pyc may redirect more carbon flux into ethanol production. We failed to obtain pyc disruption mutant using CRISPR-Cas9

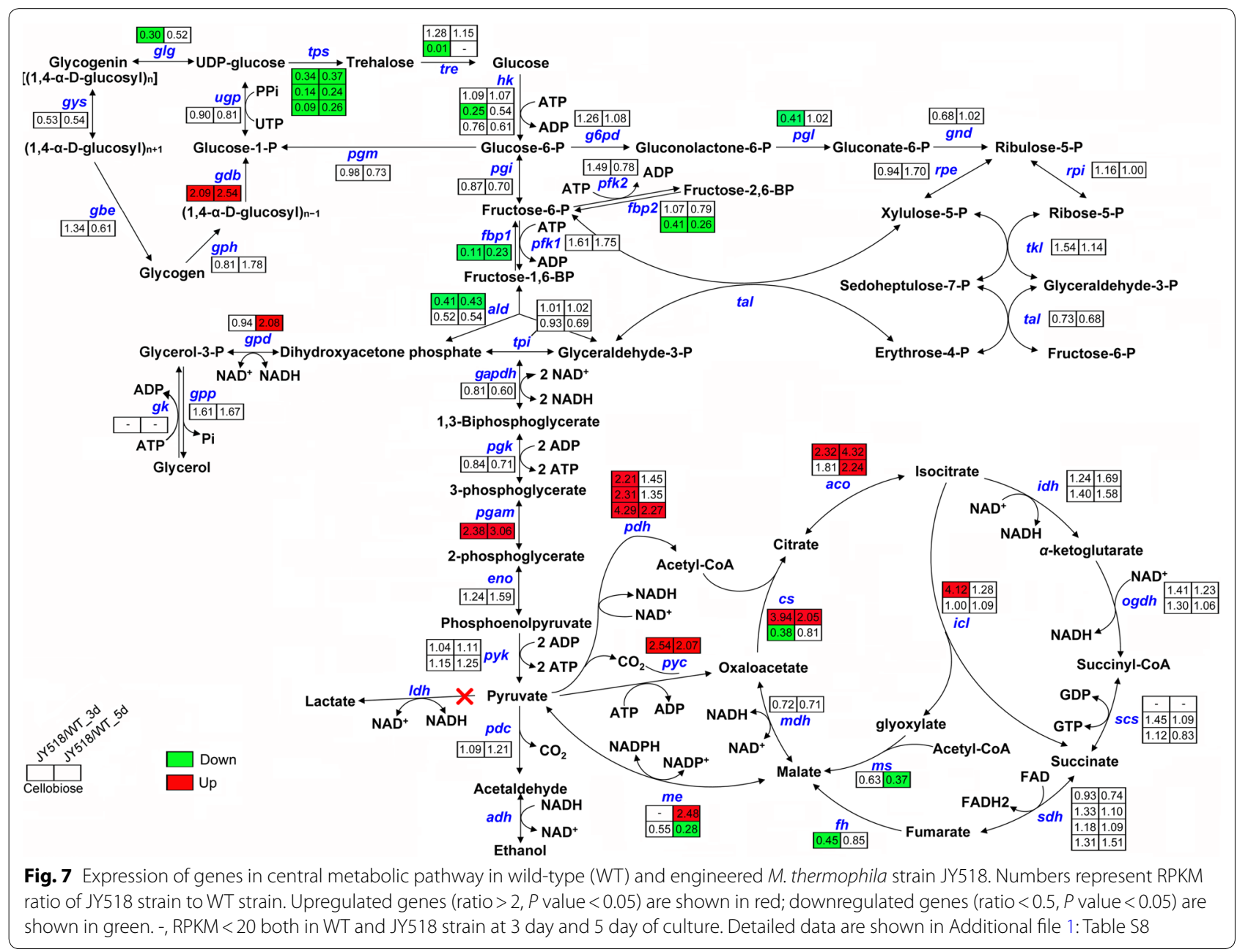


system, instead, we replaced pyc native promoter with a constitutive low-expression promoter p2298657 $(\mathrm{RPKM}<20)$ to alleviate its expression in JY518 strain. Resulting strain JY518Pyc (Fig. 8a, b) increased ethanol production by $23 \%$ compared with JY518, reach to $11.3 \mathrm{~g} / \mathrm{L}$, and the cellobiose utilization also got improved (Fig. 8c). The $p d h$ gene whose product converts pyruvate to acetyl-CoA was also upregulated in JY518 strain, it would be a good target to engineer in the future. Finally, consistent with the increased transcript levels of $p y c$ and $p d h$, most genes involved in amino acids biosynthesis whose precursor is pyruvate or $\alpha$-ketoglutarate were also upregulated in JY518 strain, especially at 5-day fermentation (Additional file 6: Fig. S5).

\section{Discussion}

Thermophilic fungi are promising resources of thermostable enzymes for industrial applications with stability at $70-80{ }^{\circ} \mathrm{C}$ [53]. M. thermophila is capable of degrading various plant-derived biomasses $[17,35]$ and is a promising biocatalyst for the production of biochemicals $[23,24]$. Besides, its high-temperature fermentation at
$45-50{ }^{\circ} \mathrm{C}$ can significantly reduce cooling costs and susceptibility to contamination. If developed successfully, the use of $M$. thermophila to produce ethanol directly from plant biomass would be a very attractive system of fungal CBP. However, its ethanol production from Avicel (cellulose) is very low, less than $0.1 \mathrm{~g} / \mathrm{L}$ in the WT $M$. thermophila strain (data not shown). Thus, targeted engineering work for fine-tuning the cellulase expression and better fermentative performance is required to construct a fungal CBP strain. Our study represents the start of such an engineering process. The engineered strain produced $11.3 \mathrm{~g} / \mathrm{L}$ ethanol, three times increased compared with the WT strain, from cellobiose, a major component of cellulose hydrolysates.

Saccharomyces cerevisiae can ferment sugars even in the presence of oxygen and at high glucose concentrations, a phenomenon referred to as the Crabtree effect [54]. As demonstrated in this study, $11.3 \mathrm{~g} / \mathrm{L}$ ethanol was produced by $M$. thermophila under non-oxygenlimited conditions, suggesting that this fungus might have the capability to be engineered as a Crabtree-positive microbe to produce ethanol well by thoroughly

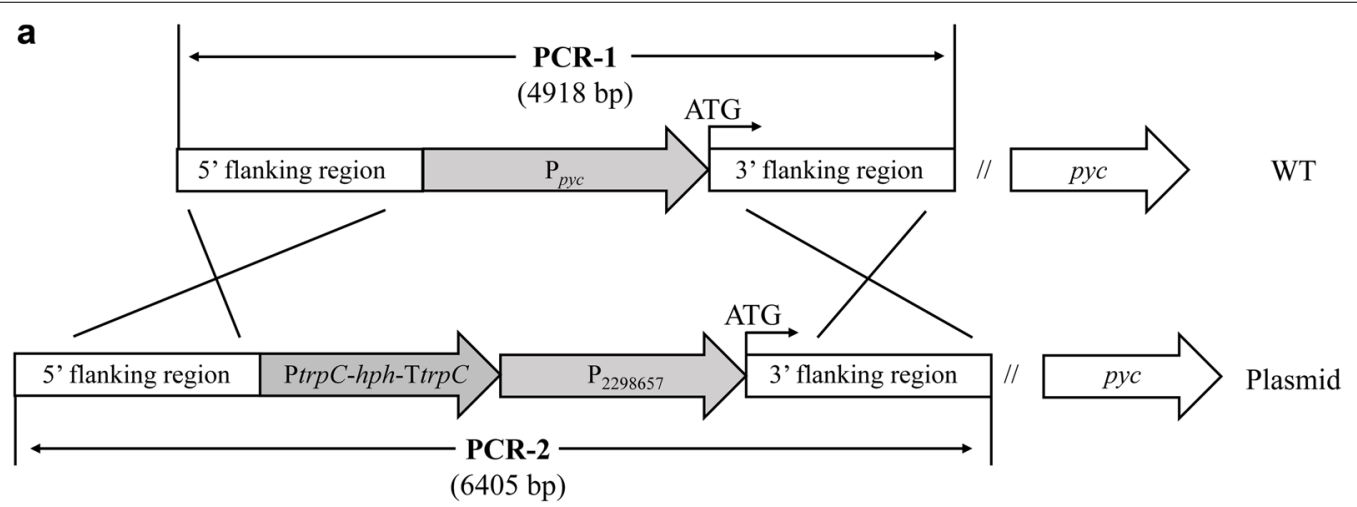

b

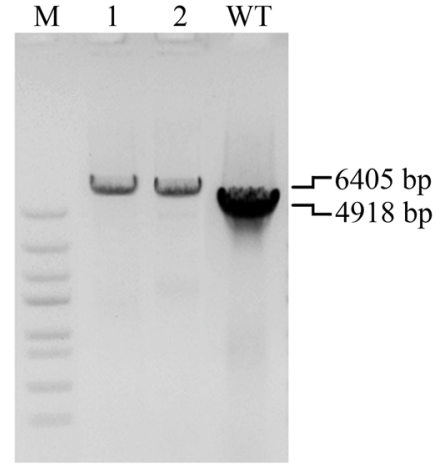

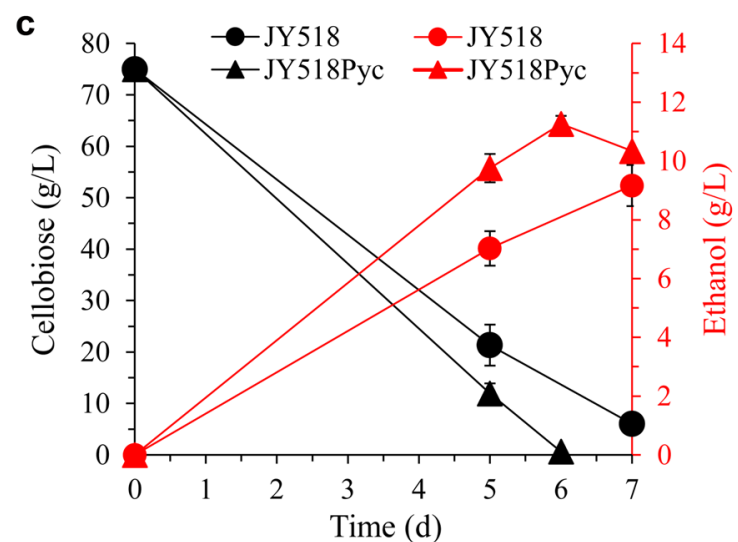

Fig. 8 Construction and characterization of JY518Pyc strain. a Strategy for construction of JY518Pyc via homologous recombination. b Confirmation of JY518Pyc by PCR. PCR1 and PCR2 were performed with the primers 2295692QC-F/2295692QC-R. The PCR product of JY518Pyc is $6.4 \mathrm{~kb}$ (Lane 1 and 2) while that of WT is $4.9 \mathrm{~kb}$. c Fermentation profile of JY518Pyc strain 
metabolic reconstruction. Unlike S. cerevisiae, $M$. thermophila cannot grow under anaerobic conditions. Its growth under semi-aerobic conditions (when the vessel was sealed with a silicon plug stopper) was significantly impaired (Additional file 7: Fig. S6a), due to the low DO level in the medium (Additional file: 7: Fig. S6b).

In $S$. cerevisiae, the balance between respiration and fermentation is the main factor affecting sugar utilization and ethanol production under aerobic conditions $[7,55,56]$. Our transcriptomic analysis of engineered $M$. thermophila showed that enhanced cellobiose utilization affects oxidation-reduction processes (Fig. 6b) as well as growth and stress responses. Therefore, manipulating certain oxidation-reduction processes might improve the efficiency of ethanol production. For example, overexpression of NADH oxidase to maintain the redox balance [57], deletion of $\mathrm{ADH}$ that involved in ethanol utilization [58] or deletion of mitochondrial NADH dehydrogenases to shift from respiratory to fermentative metabolism [59]. Further research is required to test these ideas experimentally. In cellobiose-utilizing S. cerevisiae, limited activity of Pfk1 (which catalyzes the phosphorylation of fructose-6-phosphate) was found to be a major bottleneck in cellobiose consumption [60]. Identification of rate-limiting step(s) in glycolytic pathway during cellobiose utilization would facilitate the engineering of $M$. thermophila to produce biochemicals. Multiple metabolic engineering strategies including enhancing cellobiose uptake to enhance the speed of glycolytic pathway have shown to be effective for final bio-based chemicals production in our previously engineered hyper malic acid-producing strain [24, 42]. Therefore, further increase of the glycolytic flux in combination with downregulated flux towards TCA cycle could be a good approach to increase more flux towards ethanol. Further metabolomic research needs to be employed to understand the underlying regulatory network behind biological responses at the mechanistic level.

\section{Conclusions}

The results of our study show that $M$. thermophila is a promising system for ethanol production from the biomass-derived sugar, cellobiose. Engineered strain showed three times increased ethanol production rates. This study demonstrates how a thermophilic fungus can be engineered to produce ethanol or other fuels directly from lignocellulosic substrates by fungal CBP technology.

\section{Methods}

\section{Strains, media, and growth conditions}

The $M$. thermophila strains used in this study are listed in Table 1. For sporulation, M. thermophila strains were grown on Vogel's minimal medium supplemented with $2 \%$ glucose (MM) or xylose at $37{ }^{\circ} \mathrm{C}$ for $10-15$ days. For flask culture, conidia of $M$. thermophila were inoculated into $100 \mathrm{~mL}$ fermentation medium to a final concentration of $2 \times 10^{5}$ conidia/mL in a $250-\mathrm{mL}$ Erlenmeyer flask. The fermentation medium (per liter) consisted of $75 \mathrm{~g}$ glucose or cellobiose, $10 \mathrm{~g}$ yeast extract, $0.15 \mathrm{~g} \mathrm{KH}_{2} \mathrm{PO}_{4}$, $0.15 \mathrm{~g} \mathrm{~K}_{2} \mathrm{HPO}_{4}, 0.1 \mathrm{~g} \mathrm{MgSO}_{4} \cdot 7 \mathrm{H}_{2} \mathrm{O}, 0.1 \mathrm{~g} \mathrm{CaCl}_{2} \cdot 2 \mathrm{H}_{2} \mathrm{O}$, $1 \mathrm{~mL}$ biotin $(0.1 \mathrm{~g} / \mathrm{L})$, and $1 \mathrm{~mL}$ trace elements (Vogel's salts). Escherichia coli DH5 $\alpha$ was used for plasmid amplification, and was cultured in Luria-Bertani (LB) medium supplemented with antibiotics as necessary.

\section{Construction of expression and deletion plasmids}

The primers used in this study are listed in Additional file 1: Table S1. The Adh1 gene of S. cerevisiae was amplified using the primers ScADH1-F/ScADH1-R and assembled into BamHI-digested pAN52-MtPtefTtprC using the NEB Gibson assembly kit (New England Biolabs, Ipswich, MA, USA). The $5^{\prime}$ and $3^{\prime}$ flanking regions of Mycth_38939 were amplified using the primers 38939-up-F/38939-up- $\mathrm{R}$ and 38939-down-F/38939down-R, respectively. The Pgpd-cdt1-TtrpC cassette was amplified from pAN52-MtgpdA-cdt1-TtprC using pAN52-F/TtrpC-bar-R2. The amplified 5', 3', and Pgpd$c d t 1$-TtrpC fragments were assembled and ligated into BglII-digested pCAMBIA-0380 using the NEB Gibson assembly kit, yielding pCDT1. The promoter of

Table 1 Strains used in this study

\begin{tabular}{|c|c|c|}
\hline Strain & Characteristics & Source \\
\hline Myceliophthora thermophila ATCC 42464 & Wild-type strain (WT) & ATCC \\
\hline JY144 & WT::Ptef-ScAdh1-TtrpC & This study \\
\hline JY206 & JY144::Pgpd-glt1-Tcbhl & This study \\
\hline JY518 & 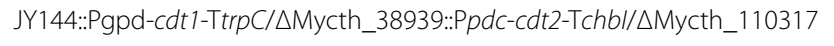 & This study \\
\hline$\triangle a e p$ & Mycth_103702 deletion mutant on WT background & This study \\
\hline JY518Рyс & Native promoter of pyc was changed to P2298657 in JY518 & This study \\
\hline
\end{tabular}

ATCC American Type Culture Collection 
the gene encoding pyruvate decarboxylase $(\mathrm{P} p d c)$ was amplified from $M$. thermophila genomic DNA using the primers Ppdc-F/Ppdc-R. The $c d t 2-\mathrm{T} c h b I$ fragment was amplified from the plasmid containing the $c d t 2-$ TcbhI cassette using the primers CDT2-F/TcbhI-R. PtrpC-bar and TtrpC were amplified using the primers P-bar-F/P-bar-R and TtrpC-bar-F/TtrpC-bar-R, respectively, and then assembled into BglII-digested pCAMBIA-0380 to produce p0380-P-bar-T. PtrpC-bar-TtrpC was amplified from p0380-P-bar-T using the primers P-bar-F3/TtrpC-bar-R. The Ppdc, cdt2-TchbI, and PtrpC-bar-TtrpC fragments were assembled into BglIIdigested PCAMBIA-0380. The $5^{\prime}$ and $3^{\prime}$ flanking regions of Mycth_110317 were amplified using the primers 110317-up-F/110317-up-R and 110317-down-F/110317down-R, respectively. The large fragment containing $\mathrm{P} p d c-c d t 2-\mathrm{T} c h b I$-PtrpC-bar-TtrpC was amplified using Ppdc-F2/TtrpC-bar-R2 and assembled together with $5^{\prime}$ and $3^{\prime}$ fragments of Myth_110317 into BglII-digested pCAMBIA-0380 to produce pCDT2. For overexpression of glt1 (NCU01633), the ORF of glt1 was amplified from cDNA of N. crassa using the primers 1633-F/1633$\mathrm{R}$ and Pgpd was amplified with the primers Pgpd-F/ Pgpd-R. The fragments glt1 and Pgpd, and the TcbhIPtrpC-bar-TtrpC cassette (amplified from pCDT2 using primers TcbhI-F/TtrpC-bar-R) were assembled into BglII-digested pCAMBIA-0380.

For aep (Mycth_103702) deletion, the $5^{\prime}$ and $3^{\prime}$ flanking regions were amplified using primers 103702-up-F/103702-up-R and 103702-down-F/103702down-R, respectively. PtrpC-bar was amplified from pPK2BarGFPb [20] using 103702-bar-F/103702bar-R. The fragment 5'-PtrpC-bar-3' was created by overlapping PCR and cloned into the pJET1.2/ blunt cloning vector. To replace the promoter of $p y c$, the $5^{\prime}$ and $3^{\prime}$ flanking regions of Ppyc were amplified using primers 2295692-up-F/2295692-up-R and 2295692-down-F/2295692-down-R, respectively. PtrpChph-TtrpC was amplified from pCSN44 (GenBank accession NO. LT726870) using HygR-F/HygR-R. p2298657 was amplified from genomic DNA of $M$. thermophila using P2298657-F/P2298657-R. The fragment 5'-PtrpC$h p h-\mathrm{T} t r p C-\mathrm{p} 2298657-3^{\prime}$ was created by overlapping PCR and cloned into the PJET1.2/blunt cloning vector.

To select for specific sgRNAs targeting ldh1 (Mycth_38939), ldh2 (Mycth_110317), aep (Mycth_103702) and promoter of pyc (Mycth_2295692), we used the sgRNACas9 tool [61] to identify sgRNA target sites with high scores. Then, a target-directed $M$. thermophila U6 promoter-driven sgRNA was created by overlapping PCR and cloned into the pJET1.2/blunt cloning vector, giving the corresponding plasmids U6pldh1-sgRNA, U6p-ldh2-sgRNA, U6p-aep-sgRNA and
U6p-Ppyc-sgRNA. The Cas9-expression PCR cassette Ptef1-Cas9-TtprC was amplified using Ptef-cas-F/TtprCcas-R from the plasmid p0380-bar-Ptef1-Cas9-TtprC [21]. All the constructed plasmids were verified by sequencing.

\section{Transformation of $M$. thermophila}

Protoplasts of $M$. thermophila were transformed as previously described [62]. For gene expression, $10 \mu \mathrm{g}$ linearized plasmid was used. For gene disruption by the CRISPR/Cas9 system, $10 \mu \mathrm{g}$ Cas9-expression PCR cassette Ptef1-Cas9-TtprC from p0380-bar-Ptef1-Cas9eGFP-TtprC [21], gRNA expression PCR cassette, and the corresponding donor fragment were mixed at a molar concentration ratio of $1: 1: 1$ and added to fungal protoplasts. The transformants were grown for 4 day on MM at $35{ }^{\circ} \mathrm{C}$ with selection for neo resistance using geneticin $(100 \mu \mathrm{g} / \mathrm{mL})$, bar resistance using phosphinothricin $(100 \mu \mathrm{g} / \mathrm{mL})$, or $h p h$ resistance using hygromycin B $(50 \mu \mathrm{g} / \mathrm{mL})$. The presence of the transgene was confirmed by PCR.

\section{Analytical methods}

Cultures were sampled frequently throughout fermentation to determine biomass, sugar uptake, and ethanol yield. Sugars (cellobiose and glucose), glycerol and ethanol in the supernatant were quantified by high-performance liquid chromatography (HPLC) with an e2695 instrument (Waters, Manchester, United Kingdom) equipped with a Waters 2414 refractive index detector and an Aminex HPX-87H column (Bio-Rad, Hercules, CA, USA) at $50{ }^{\circ} \mathrm{C}$. The mobile phase was $5 \mathrm{mM} \mathrm{H}_{2} \mathrm{SO}_{4}$ with a constant flow rate of $0.5 \mathrm{~mL} / \mathrm{min}$.

\section{RNA extraction, sequencing, and data analysis}

Myceliophthora thermophila strains were inoculated into fermentation medium containing $7.5 \%$ carbon source and cultured at $45{ }^{\circ} \mathrm{C}$. Mycelia were collected at 3 days and 5 days of culture, immediately homogenized in liquid nitrogen, and then stored at $-80^{\circ} \mathrm{C}$. Total RNA was extracted as described previously [34]. For each condition, two biological duplicates were sequenced using the Illumina HiSeq ${ }^{\text {TM }} 2000$ platform (Illumina, San Diego, CA, USA). Data were analyzed as described previously [63]. Genes with reads per kilobase million (RPKM) value $>20$, fold change $>2.0$, and DESeq $P_{\text {adj }}$ value $<0.05$ were considered to differentially express between growth conditions.

\section{Sugar transport assay}

For sugar transport assay, conidia of $M$. thermophila were inoculated into $100 \mathrm{~mL}$ fermentation medium containing $3 \%$ glucose or cellobiose to a final concentration of 
$5 \times 10^{5}$ conidia $/ \mathrm{mL}$ in a $250-\mathrm{mL}$ Erlenmeyer flask. After cultivation at $45^{\circ} \mathrm{C}$ and $150 \mathrm{rpm}$ for $16 \mathrm{~h}$, mycelia were transferred to the same fresh media. Samples were taken at $4 \mathrm{~h}$ for determination of sugar concentration and DCW.

\section{Growth test}

Conidia of $M$. thermophila were collected from corresponding strains, filtered and adjusted to $1 \times 10^{6}$ conidia/ $\mathrm{mL}$. Then $1 \mu \mathrm{L}$ of the suspension was plated on Vogel's minimal medium supplemented with $2 \%$ glucose or cellobiose at $45^{\circ} \mathrm{C}$ or $55^{\circ} \mathrm{C}$ for 4 days. $\mathrm{H}_{2} \mathrm{O}_{2}$ was added to the media to a final concentration of $1 \mathrm{mM}$ when necessary.

For comparison of growth of WT and JY518 under different temperatures, conidia were inoculated into fermentation medium containing $7.5 \%$ cellobiose and cultivated at $45{ }^{\circ} \mathrm{C}, 150 \mathrm{rpm}$ for $16 \mathrm{~h}$, then placed at $55{ }^{\circ} \mathrm{C}$. Samples were taken at different intervals for determination of DCW.

To determine the growth of WT under normal and oxygen-limited condition, conidia were inoculated into fermentation medium containing $7.5 \%$ glucose to a final concentration of $2 \times 10^{5}$ conidia/mL in a $250-\mathrm{mL}$ Erlenmeyer flask with (limited) or without (normal) a plug stopper. Samples were taken at 3 day and 5 day to determine DCW and DO level. DO was measured by a dissolved oxygen meter (Leici JPSJ-605, China).

\section{Determining copy numbers by RT-qPCR}

To determine the copy numbers of the integrated neo and bar marker genes, fungal genomic DNAs were extracted and used as templates for RT-qPCR. The primers used are listed in Additional file 1: Table S1. The actin gene (MYCTH_2314852) was used as an internal control. The qPCR was performed as described previously $[21,23]$.

\section{Enzymatic activity assay}

At 5-day fermentation using $7.5 \%$ glucose, mycelia of WT and JY144 strains were harvested and homogenated on ice immediately. After centrifugation at $16,000 \mathrm{~g}$ and $4{ }^{\circ} \mathrm{C}$ for $20 \mathrm{~min}$, the supernatants were used for ADH activity assay. Protein concentration of supernatants was determined using a Bio-Rad DC protein assay kit (Bio$\mathrm{Rad})$. The final reaction mixture was $600 \mu \mathrm{L}$ consisting of $50 \mathrm{mM}$ Tris- $\mathrm{HCl} \mathrm{pH}$ 8.0, $2.5 \mathrm{mM} \mathrm{NADH}, 300 \mathrm{mM}$ acetaldehyde and $30 \mu \mathrm{g}$ total protein. Assays were performed at $25^{\circ} \mathrm{C}$ and the consumption of $\mathrm{NADH}$ was immediately measured at a wavelength of $340 \mathrm{~nm}$ using a UV detector. Total ADH activity was defined as the amount of total protein required to consume $1 \mu \mathrm{mol} \mathrm{NADH}$ per minute under the above conditions.

\section{Supplementary information}

Supplementary information accompanies this paper at https://doi. org/10.1186/s13068-020-1661-y.

\section{Additional file 1. Additional tables.}

Additional file 2: Fig. S1. Construction and characterization of $\triangle a e p$ mutants. a Diagnostic PCR of the transformants using primers KO103702YZ-F/KO103702YZ-R. $\triangle$ aep mutants displayed a 1052 bp product while WT displayed a $786 \mathrm{bp}$ product. b Four $\triangle a e p$ mutants were randomly selected for growth assay. Plates were cultivated at $37^{\circ} \mathrm{C}$ for 4 day. Ethanol production (c) and biomass (d) at 7 day fermentation were determined.

Additional file 3: Fig. S2. Determination of ethanol production and copy number of transformants. a Ethanol production by transformants overexpressing ScAdh1. b Ethanol production by transformants overexpressing glt-1. The transformants were fermented for 5 day. c Assay of ScAdh 1 copy number in transformants by RT-qPCR. d Assay of g/t-1 copy number in transformants by RT-qPCR.

Additional file 4: Fig. S3. Response of JY518 strain to (a) $\mathrm{H}_{2} \mathrm{O}_{2}$-induced oxidative stress and heat stress on medium using cellobiose as carbon source and (b) heat stress during fermentation on cellobiose.

Additional file 5: Fig. S4. Glycerol production of corresponding strain during fermentation on glucose and cellobiose at 5 day and 7 day.

Additional file 6: Fig. S5. Expression of genes involved in amino acid biosynthesis in WT and JY518 strain. Numbers represent RPKM ratio of JY518 strain to WT strain. Upregulated genes (ratio $>2$, P value $<0.05$ ) are shown in red boxes. Detailed data are shown in Additional file 1: Table S8.

Additional file 7: Fig. S6. Effect of dissolved oxygen (DO) on growth of $M$. thermophila. a Biomass of WT strain grown on non-oxygen limited (normal) and oxygen limited conditions. b DO levels of cultures in Erlenmeyer flask without (normal) or with (limited) a plug stopper. Fermentation media with $7.5 \%$ glucose were used.

\section{Abbreviations}

ORF: Open reading frame; DCW: Dry cell weight; DO: Dissolved oxygen; CBP: Consolidated bioprocessing; CCR: Carbon catabolite repression; GO: Gene Ontology; WT: Wild type.

\section{Acknowledgements}

This research was supported by National Key R\&D Program of China (2018YFA0900500), National Natural Science Foundation of China (31670042, $31701079,31471186)$ and the Chinese Academy of Sciences (XDA21060900).

\section{Authors' contributions}

CT and JYL designed the experiments. JYL, YZ, JGL and TS performed metabolic engineering experiments and analyzed the data. CT and JL wrote the manuscript. All authors read and approved the final manuscript.

\section{Funding}

This research was supported by National Key R\&D Program of China (2018YFA0900500), National Natural Science Foundation of China (31670042, $31701079,31471186)$ and the Chinese Academy of Sciences (XDA21060900).

\section{Availability of data and materials}

All data generated or analyzed during this study are included in this published article and its additional files.

\section{Ethics approval and consent to participate} Not applicable.

\section{Consent for publication \\ Not applicable.}

\section{Competing interests}

A patent involved in ethanol production using thermophilic fungus was submitted by the institute of authors. 


\section{Author details}

${ }^{1}$ Key Laboratory of Systems Microbial Biotechnology, Tianjin Institute of Industrial Biotechnology, Chinese Academy of Sciences, Tianjin 300308, China.

${ }^{2}$ University of Chinese Academy of Sciences, Beijing 100049, China.

\section{Received: 1 August 2019 Accepted: 21 January 2020}

Published online: 01 February 2020

\section{References}

1. Klemm D, Heublein B, Fink HP, Bohn A. Cellulose: fascinating biopolymer and sustainable raw material. Angew Chem Int Ed Engl. 2005;44(22):3358-93.

2. Carroll A, Somerville C. Cellulosic biofuels. Annu Rev Plant Biol. 2009;60:165-82.

3. Fan LH, Zhang ZJ, Mei S, Lu YY, Li M, Wang ZY, Yang JG, Yang ST, Tan TW. Engineering yeast with bifunctional minicellulosome and cellodextrin pathway for co-utilization of cellulose-mixed sugars. Biotechnol Biofuels. 2016:9:137.

4. Galazka JM, Tian C, Beeson WT, Martinez B, Glass NL, Cate JH. Cellodextrin transport in yeast for improved biofuel production. Science. 2010;330(6000):84-6.

5. Kim H, Lee WH, Galazka JM, Cate JH, Jin YS. Analysis of cellodextrin transporters from Neurospora crassa in Saccharomyces cerevisiae for cellobiose fermentation. Appl Microbiol Biotechnol. 2014;98(3):1087-94.

6. Sadie CJ, Rose SH, den Haan R, van Zyl WH. Co-expression of a cellobiose phosphorylase and lactose permease enables intracellular cellobiose utilisation by Saccharomyces cerevisiae. Appl Microbiol Biotechnol. 2011;90(4):1373-80

7. Lin Y, Chomvong K, Acosta-Sampson L, Estrela R, Galazka JM, Kim SR, Jin YS, Cate JH. Leveraging transcription factors to speed cellobiose fermentation by Saccharomyces cerevisiae. Biotechnol Biofuels. 2014;7(1):126.

8. Ha SJ, Galazka JM, Kim SR, Choi JH, Yang X, Seo JH, Glass NL, Cate JH, Jin YS. Engineered Saccharomyces cerevisiae capable of simultaneous cellobiose and xylose fermentation. Proc Natl Acad Sci USA. 2011;108(2):504-9.

9. Du J, Yuan Y, Si T, Lian J, Zhao H. Customized optimization of metabolic pathways by combinatorial transcriptional engineering. Nucleic Acids Res. 2012;40(18):e142

10. Ha SJ, Galazka JM, Joong OhE, Kordic V, Kim H, Jin YS, Cate JH. Energetic benefits and rapid cellobiose fermentation by Saccharomyces cerevisiae expressing cellobiose phosphorylase and mutant cellodextrin transporters. Metab Eng. 2013;15:134-43.

11. Lian J, Li Y, HamediRad M, Zhao H. Directed evolution of a cellodextrin transporter for improved biofuel production under anaerobic conditions in Saccharomyces cerevisiae. Biotechnol Bioeng. 2014;111(8):1521-31.

12. Kim H, Oh EJ, Lane ST, Lee WH, Cate JH, Jin YS. Enhanced cellobiose fermentation by engineered Saccharomyces cerevisiae expressing a mutant cellodextrin facilitator and cellobiose phosphorylase. J Biotechnol. 2018:275:53-9.

13. Eriksen DT, Hsieh PC, Lynn P, Zhao H. Directed evolution of a cellobiose utilization pathway in Saccharomyces cerevisiae by simultaneously engineering multiple proteins. Microb Cell Fact. 2013;12:61.

14. Oh EJ, Skerker JM, Kim SR, Wei N, Turner TL, Maurer MJ, Arkin AP, Jin YS. Gene amplification on demand accelerates cellobiose utilization in engineered Saccharomyces cerevisiae. Appl Environ Microbiol. 2016;82(12):3631-9.

15. Bae YH, Kang KH, Jin YS, Seo JH. Molecular cloning and expression of fungal cellobiose transporters and $\beta$-glucosidases conferring efficient cellobiose fermentation in Saccharomyces cerevisiae. J Biotechnol. 2014;169:34-41.

16. Ha SJ, Kim H, Lin Y, Jang MU, Galazka JM, Kim TJ, Cate JH, Jin YS. Single amino acid substitutions in HXT24 from Scheffersomyces stipitis lead to improved cellobiose fermentation by engineered Saccharomyces cerevisiae. Appl Environ Microbiol. 2013;79(5):1500-7.

17. Berka RM, Grigoriev IV, Otillar R, Salamov A, Grimwood J, Reid I, Ishmael N, John T, Darmond C, Moisan MC, et al. Comparative genomic analysis of the thermophilic biomass-degrading fungi Myceliophthora thermophila and Thielavia terrestris. Nat Biotechnol. 2011;29(10):922-7.
18. Karnaouri A, Topakas E, Antonopoulou I, Christakopoulos P. Genomic insights into the fungal lignocellulolytic system of Myceliophthora thermophila. Front Microbiol. 2014;5:281.

19. Visser H, Joosten V, Punt PJ, Gusakov AV, Olson PT, Joosten R, Bartels J, Visser J. Development of a mature fungal technology and production platform for industrial enzymes based on a Myceliophthora thermophila isolate, previously known as Chrysosporium lucknowense C1. Ind Biotechnol. 2011;7:214-23.

20. Xu J, Li J, Lin L, Liu Q, Sun W, Huang B, Tian C. Development of genetic tools for Myceliophthora thermophila. BMC Biotechnol. 2015;15:35.

21. Liu Q, Gao R, Li J, Lin L, Zhao J, Sun W, Tian C. Development of a genomeediting CRISPR/Cas9 system in thermophilic fungal Myceliophthora species and its application to hyper-cellulase production strain engineering. Biotechnol Biofuels. 2017;10:1.

22. Liu Q, Zhang Y, Li F, Li J, Sun W, Tian C. Upgrading of efficient and scalable CRISPR-Cas-mediated technology for genetic engineering in thermophilic fungus Myceliophthora thermophila. Biotechnol Biofuels. 2019;12:293.

23. Gu S, Li J, Chen B, Sun T, Liu Q, Xiao D, Tian C. Metabolic engineering of the thermophilic filamentous fungus Myceliophthora thermophila to produce fumaric acid. Biotechnol Biofuels. 2018;11:323.

24. Li J, Lin L, Sun T, Xu J, Ji J, Liu Q, Tian C. Direct production of commodity chemicals from lignocellulose using Myceliophthora thermophila. Metab Eng. 2019. https://doi.org/10.1016/j.ymben.2019.05.007.

25. Anders $S$, Huber W. Differential expression analysis for sequence count data. Genome Biol. 2010;11:R106.

26. Liu Q, Li J, Gao R, Li J, Ma G, Tian C. CLR-4, a novel conserved transcription factor for cellulase gene expression in ascomycete fungi. Mol Microbiol. 2019:111(2):373-94

27. Coradetti ST, Craig JP, Xiong Y, Shock T, Tian C, Glass NL. Conserved and essential transcription factors for cellulase gene expression in ascomycete fungi. Proc Natl Acad Sci USA. 2012;109(19):7397-402.

28. Huberman LB, Coradetti ST, Glass NL. Network of nutrient-sensing pathways and a conserved kinase cascade integrate osmolarity and carbon sensing in Neurospora crassa. Proc Natl Acad Sci USA. 2017;114(41):E8665-74.

29. Sun J, Tian C, Diamond S, Glass NL. Deciphering transcriptional regulatory mechanisms associated with hemicellulose degradation in Neurospora crassa. Eukaryot Cell. 2012;11(4):482-93.

30. Znameroski EA, Li X, Tsai JC, Galazka JM, Glass NL, Cate JH. Evidence for transceptor function of cellodextrin transporters in Neurospora crassa. J Biol Chem. 2014;289(5):2610-9.

31. Cai P, Wang B, Ji J, Jiang Y, Wan L, Tian C, Ma Y. The putative cellodextrin transporter-like protein CLP1 is involved in cellulase induction in Neurospora crassa. J Biol Chem. 2015;290(2):788-96.

32. Gomi K, Akeno T, Minetoki T, Ozeki K, Kumagai C, Okazaki N, limura Y. Molecular cloning and characterization of a transcriptional activator gene, amyR, involved in the amylolytic gene expression in Aspergillus oryzae. Biosci Biotechnol Biochem. 2000;64(4):816-27.

33. Xiong Y, Wu VW, Lubbe A, Qin L, Deng S, Kennedy M, Bauer D, Singan VR, Barry K, Northen TR, et al. A fungal transcription factor essential for starch degradation affects integration of carbon and nitrogen metabolism. PLoS Genet. 2017;13(5):e1006737.

34. Xu G, Li J, Liu Q, Sun W, Jiang M, Tian C. Transcriptional analysis of Myceliophthora thermophila on soluble starch and role of regulator AmyR on polysaccharide degradation. Bioresour Technol. 2018;265:558-62.

35. Kolbusz MA, Di Falco M, Ishmael N, Marqueteau S, Moisan MC, Baptista CDS, Powlowski J, Tsang A. Transcriptome and exoproteome analysis of utilization of plant-derived biomass by Myceliophthora thermophila. Fungal Genet Biol. 2014;72:10-20.

36. Tian C, Beeson WT, lavarone AT, Sun J, Marletta MA, Cate JH, Glass NL. Systems analysis of plant cell wall degradation by the model filamentous fungus Neurospora crassa. Proc Natl Acad Sci USA. 2009;106(52):22157-62.

37. Wang B, Cai P, Sun W, Li J, Tian C, Ma Y. A transcriptomic analysis of Neurospora crassa using five major crop residues and the novel role of the sporulation regulator rca-1 in lignocellulase production. Biotechnol Biofuels. 2015;8:21.

38. Li S, Ha SJ, Kim HJ, Galazka JM, Cate JH, Jin YS, Zhao H. Investigation of the functional role of aldose 1-epimerase in engineered cellobiose utilization. J Biotechnol. 2013;168(1):1-6. 
39. Znameroski EA, Coradetti ST, Roche CM, Tsai JC, lavarone AT, Cate JH, Glass NL. Induction of lignocellulose-degrading enzymes in Neurospora crassa by cellodextrins. Proc Natl Acad Sci USA. 2012;109(16):6012-7.

40. Nihira T, Saito Y, Nishimoto M, Kitaoka M, Igarashi K, Ohtsubo K, Nakai H. Discovery of cellobionic acid phosphorylase in cellulolytic bacteria and fungi. FEBS Lett. 2013;587(21):3556-61.

41. Hildebrand A, Szewczyk E, Lin H, Kasuga T, Fan Z. Engineering Neurospora crassa for improved cellobiose and cellobionate production. Appl Environ Microbiol. 2015;81(2):597-603.

42. Li J, Gu S, Zhao Z, Chen B, Liu Q, Sun T, Sun W, Tian C. Dissecting cellobiose metabolic pathway and its application in biorefinery through consolidated bioprocessing in Myceliophthora thermophila. Fungal Biol Biotechnol. 2019;6(1):21

43. van Heerden JH, Wortel MT, Bruggeman FJ, Heijnen JJ, Bollen YJ, Planque R, Hulshof J, O'Toole TG, Wahl SA, Teusink B. Lost in transition: startup of glycolysis yields subpopulations of nongrowing cells. Science. 2014;343(6174):1245114.

44. Eguchi Y, Makanae K, Hasunuma T, Ishibashi Y, Kito K, Moriya H. Estimating the protein burden limit of yeast cells by measuring the expression limits of glycolytic proteins. eLife. 2018;7:e34595.

45. Kasahara K, Miyamoto T, Fujimoto T, Oguri H, Tokiwano T, Oikawa H, Ebizuka Y, Fujii I. Solanapyrone synthase, a possible Diels-Alderase and iterative type I polyketide synthase encoded in a biosynthetic gene cluster from Alternaria solani. ChemBioChem. 2010;11(9):1245-52.

46. Ge L, Seah SY. Heterologous expression, purification, and characterization of an L-ornithine N(5)-hydroxylase involved in pyoverdine siderophore biosynthesis in Pseudomonas aeruginosa. J Bacteriol. 2006;188(20):7205-10.

47. Hainzl O, Lapina MC, Buchner J, Richter K. The charged linker region is an important regulator of Hsp90 function. J Biol Chem. 2009;284(34):22559-67.

48. Panaretou B, Prodromou C, Roe SM, O'Brien R, Ladbury JE, Piper PW, Pearl LH. ATP binding and hydrolysis are essential to the function of the Hsp90 molecular chaperone in vivo. EMBO J. 1998;17(16):4829-36.

49. Richter K, Moser S, Hagn F, Friedrich R, Hainzl O, Heller M, Schlee S, Kessler $\mathrm{H}$, Reinstein J, Buchner J. Intrinsic inhibition of the Hsp90 ATPase activity. J Biol Chem. 2006;281(16):11301-11.

50. Iwahashi H, Nwaka S, Obuchi K, Komatsu Y. Evidence for the interplay between trehalose metabolism and Hsp104 in yeast. Appl Environ Microbiol. 1998;64(11):4614-7.

51. lanutsevich EA, Danilova OA, Groza NV, Kotlova ER, Tereshina VM. Heat shock response of thermophilic fungi: membrane lipids and soluble carbohydrates under elevated temperatures. Microbiology. 2016;162(6):989-99.
52. Singer MA, Lindquist S. Multiple effects of trehalose on protein folding in vitro and in vivo. Mol Cell. 1998;1 (5):639-48.

53. Patel AK, Singhania RR, Sim SJ, Pandey A. Thermostable cellulases: current status and perspectives. Bioresour Technol. 2019;279:385-92.

54. Crabtree HG. Observations on the carbohydrate metabolism of tumours. Biochem J. 1929;23:536-45.

55. Otterstedt K, Larsson C, Bill RM, Stahlberg A, Boles E, Hohmann S, Gustafsson L. Switching the mode of metabolism in the yeast Saccharomyces cerevisiae. EMBO Rep. 2004;5(5):532-7.

56. van Maris AJ, Bakker BM, Brandt M, Boorsma A, de Mattos MJ, Grivell LA, Pronk JT, Blom J. Modulating the distribution of fluxes among respiration and fermentation by overexpression of HAP4 in Saccharomyces cerevisiae. FEMS Yeast Res. 2001;1(2):139-49.

57. Shi X, Zou Y, Chen Y, Ying H. Overexpression of THI4 and HAP4 improves glucose metabolism and ethanol production in Saccharomyces cerevisiae. Front Microbiol. 2018;9:1444.

58. Xue T, Liu K, Chen D, Yuan X, Fang J, Yan H, Huang L, Chen Y, He W. Improved bioethanol production using CRISPR/Cas9 to disrupt the $\mathrm{ADH} 2$ gene in Saccharomyces cerevisiae. World J Microbiol Biotechnol. 2018:34(10):154.

59. Gonzalez-Siso MI, Tourino A, Vizoso A, Pereira-Rodriguez A, RodriguezBelmonte E, Becerra M, Cerdan ME. Improved bioethanol production in an engineered Kluyveromyces lactis strain shifted from respiratory to fermentative metabolism by deletion of NDI1. Microb Biotechnol. 2015;8(2):319-30.

60. Chomvong K, Benjamin DI, Nomura DK, Cate JH. Cellobiose consumption uncouples extracellular glucose sensing and glucose metabolism in Saccharomyces cerevisiae. mBio. 2017;8(4):e00855.

61. Xie S, Shen B, Zhang C, Huang X, Zhang Y. sgRNAcas9: a software package for designing CRISPR sgRNA and evaluating potential off-target cleavage sites. PLOS ONE. 2014;9(6):e100448.

62. Wang J, Wu Y, Gong Y, Yu S, Liu G. Enhancing xylanase production in the thermophilic fungus Myceliophthora thermophila by homologous overexpression of Mtxyr1. J Ind Microbiol Biotechnol. 2015;42(9):1233-41.

63. Wang B, Li J, Gao J, Cai P, Han X, Tian C. Identification and characterization of the glucose dual-affinity transport system in Neurospora crassa: pleiotropic roles in nutrient transport, signaling, and carbon catabolite repression. Biotechnol Biofuels. 2017;10:17.

\section{Publisher's Note}

Springer Nature remains neutral with regard to jurisdictional claims in published maps and institutional affiliations.
Ready to submit your research? Choose BMC and benefit from:

- fast, convenient online submission

- thorough peer review by experienced researchers in your field

- rapid publication on acceptance

- support for research data, including large and complex data types

- gold Open Access which fosters wider collaboration and increased citations

- maximum visibility for your research: over $100 \mathrm{M}$ website views per year

At BMC, research is always in progress.

Learn more biomedcentral.com/submissions 